Info Artikel Diterima Oktober 2018

Disetujui Januari 2019

Dipublikasikan April 2019

\title{
FAKTOR-FAKTOR YANG MEMPENGARUHI PENDAPATAN \\ USAHATANI TEBU (Sacharum officinarum L) \\ DI KECAMATAN PANGKAH KABUPATEN TEGAL
}

\author{
THE FACTORS WHICH AFFECTING SUGARCANE \\ (Sacharum officinarum L) FARMERS INCOME LEVEL \\ IN PANGKAH DISTRICT TEGAL REGENCY
}

\author{
Rahmat Abi Alfatah, Dewi Hastuti, Rossi Prabowo \\ Program Studi Agribisnis Fakultas Pertanian \\ Universitas Wahid Hasyim Semarang
}

Email: rahmatabialfatah10@gmail.com

\begin{abstract}
Purpose of this research is to know the acceptance level, income and the factors that is affecting the level of sugarcane farmers income. Regional sampling method and respondent sampling are conducted by purposive sampling method which is set a lend area sampled is $1-3,5$ acres. Number of samples are taken by 59 respondents of the sugarcane farmers who are scattered in several villages at the Pangkah sub District. The analysis method used is descriptive analysis, cost analysis, revenue, income and multiple linear regression. The result of the study indicate that the average cost is obtained by the total cost Rp. 54.953.884. The revenue is obtained Rp. 82.979.127, while the income earned Rp. 28.025.243 every harvest time. The result of multiple liniear regression is known that the determination coefficient $\left(\mathrm{R}^{2}\right)$ is 0.848 . Meanwhile the result of testing $t$ test obtained by educational factors have significant 0.042 which mean have a real impact to income at $5 \%$ real level. The ages factors have significant 0.001 which mean have a real impact to income at $1 \%$ real level. The land area have significant 0.044 which mean have a real impact to income at $5 \%$ real level. The labours have significant 0.001 which mean have a real impact to income at $1 \%$ real level. The amount of production have significant 0.000 which mean have a real impact to income at $1 \%$ real level.
\end{abstract}

Keywords: Income, Sugarcane, farmers, Regression, Pangkah

\begin{abstract}
ABSTRAK
Tujuan Penelitian adalah untuk mengetahui tingkat penerimaan dan pendapatan serta faktor-faktor yang mempengaruhi pendapatan usahatani tebu. Metode pengambilan sampel daerah dan pengambilan sampel responden dilakukan dengan metode purposive sampling yaitu menetapkan luas lahan yang disampling $1-3,5$ ha. Jumlah sampel yang diambil sebanyak 59 responden petani tebu yang tersebar di beberapa desa yang ada di Kecamatan Pangkah. Metode
\end{abstract}


analisis yang digunakan adalah analisis deskriptif, analisis biaya, penerimaan dan pendapatan, serta regresi linier berganda. Hasil penelitian menunjukkan bahwa rata-rata biaya diperoleh biaya total sebesar Rp. 54.953.884,-- Penerimaan diperoleh Rp. 82.979.127,-- sedangkan pendapatan diperoleh Rp. 28.025.243,- per satu kali musim panen. Hasil regresi linier berganda diketahui bahwa nilai koefisien determinasi $\left(\mathrm{R}^{2}\right)$ 0,848. Sementara itu hasil pengujian uji t diperoleh faktor pendidikan mempunyai signifikan 0,042 yang berarti berpengaruh nyata terhadap pendapatan pada taraf nyata 5\%. Faktor umur mempunyai nilai signifikan 0,001 yang berarti berpengaruh sangat nyata terhadap pendapatan pada taraf sangat nyata $1 \%$. Faktor luas lahan mempunyai nilai signifikan 0,044 yang berarti berpengaruh nyata terhadap pendapatan pada taraf nyata $5 \%$. Faktor tenaga kerja mempunyai nilai signifikan 0,001 yang berarti berpengaruh sangat nyata terhadap pendapatan pada taraf $1 \%$. Faktor jumlah produksi mempunyai nilai signifikan 0,000 yang berarti berpengaruh sangat nyata terhadap pendapatan pada taraf $1 \%$.

Kata kunci: Pendapatan, Tebu, Petani, Regresi, Pangkah.

\section{PENDAHULUAN}

Sektor pertanian merupakan salah satu sektor yang memiliki peranan penting dalam pertumbuhan perekonomian Indonesia. Sektor pertanian menurut Soetrisno (2002) tidak hanya terdiri atas sub sektor pertanian dan sub sektor pangan, tetapi juga sub sektor peternakan, dan sub sektor perkebunan. Di sisi internal sektor pertanian, usahatani sendiri belum mendukung ke arah pelaksanaan pertanian berkelanjutan (Prabowo, 2010). Potensi dari beberapa sub sektor pertanian tersebut perlu dimaksimalkan untuk mencapai kesejahteraan masyarakat luas pada umumnya dan petani pada khususnya. Salah satunya adalah sub sektor perkebunan. Tanaman tebu (Saccharum officinarum L) merupakan bahan dasar pembuatan gula yang sudah menjadi kebutuhan industri dan rumah tangga yang didalam batang tebu terkandung $20 \%$ cairan gula (Royyani dan Lestari, 2009).

Kabupaten Tegal merupakan salah satu daerah yang menyumbang luasan areal tebu untuk Jawa Tengah pada tahun 2016 mencapai 3.264,53 hektar. Menurut BPS Kabupaten Tegal (2017) Kecamatan Pangkah merupakan daerah dengan luas areal tebu terbanyak di Kabupaten Tegal yang mempunyai luas 732,29 hektar, dengan produksi sebesar 3.588,22 ton dan produktivitas 4,90 ton/hektar. Mengingat tebu merupakan komoditas yang masuk kedalam tanaman semusim yang membutuhkan waktu hampir satu tahun untuk menikmati panennya, tentunya serangkaian kegiatan budidaya yang meliputi on farm maupun off farm yang ada didalamnya harus dilakukan sesuai dengan standar yang benar, agar petani mampu memperoleh hasil yang maksimal. Seringkali penanaman tebu yang belum memenuhi standar menyebabkan kerugian ditingkat petani.

\section{BAHAN DAN METODE}

Metode yang dipakai dalam penelitian ini menggunakan metode deskriptif analisis. Metode pemilihan lokasi dan pengambilan responden dilakukan dengan teknik purposive sampling, yaitu dengan sengaja dilakukan di Kecamatan 
Pangkah, karena kecamatan tersebut merupakan kecamatan dengan luas areal tebu paling tinggi dari 23 kecamatan yang ada, dan pengambilan responden dilakukan berdasarkan petani yang menanam tebu varietas Bululawang (BL) dengan lahan seluas $1-3,5$ ha yang berada di Desa Curug 1 orang, Desa Depok 1 orang, Desa Dermasandi 2 orang, Desa Dukuhsembung 1 orang, Desa Grobog Kulon 11 orang, Desa Grobog Wetan 1 orang, Desa Kalikangkung 6 orang, Desa Kendalserut 6 orang, Desa Pangkah 7 orang, Desa Pecabean 3 orang, Desa Penusupan 14 orang, Desa Talok 6 orang. Total responden 59 orang. Uji yang dilakukan meliputi analisis biaya tetap dan analisis biaya variabel, analisis penerimaan, analisis pendapatan, dan analisis regresi linier berganda.

\section{HASIL DAN PEMBAHASAN}

\section{Gambaran Umum Lokasi Penelitian}

Kecamatan Pangkah terdiri atas 23 Desa, 101 RW, 486 RT, dan 6 perdukuhan dengan batas wilayah Kecamatan Pangkah adalah sebagai berikut:

Sebelah Utara : Kecamatan Tarub, Talang, Adiwerna

Sebelah Selatan : Kecamatan Lebaksiu dan Jatinegara

Sebelah Barat : Kecamatan Slawi

Sebelah Timur : Kecamatan Kedungbanteng

Total luas wilayah Kecamatan Pangkah yaitu 3.508,83 ha terdiri dari luas lahan sawah sebesar 1.774,64 ha. Sedangkan lahan bukan sawah, terbagi menjadi beberapa penggunaan, antara lain: bangunan dan Pekarangan dengan luas 844,15 ha. Tegal atau kebun memiliki luas 586,74 ha. Hutan Negara memiliki luas 115 ha. Makam, lapangan dan kolam memiliki luas 188,30 ha.

\section{Jumlah Penduduk Berdasarkan Jenis Kelamin}
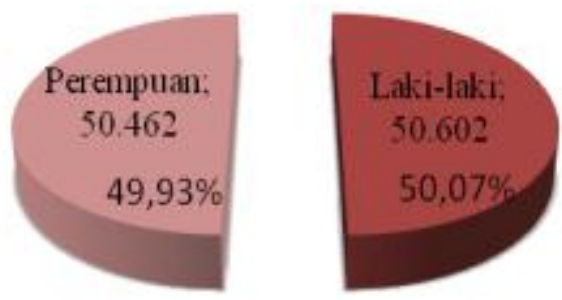

\section{Gambar 1 Penduduk Kecamata Pangkah}

Tabel 1. Jumlah Penduduk Menurut Umur di Kecamatan Pangkah Kabupaten Tegal

\begin{tabular}{lrr}
\hline Umur (Tahun) & Jumlah & Persentase (\%) \\
\hline $0-14$ & 27.869 & 27,57 \\
$15-64$ & 67.336 & 66,63 \\
$65+$ & 5.859 & 5,80 \\
Jumlah & $\mathbf{1 0 1 . 0 6 4}$ & $\mathbf{1 0 0 , 0 0}$ \\
\hline
\end{tabular}

Sumber : BPS Kabupaten Tegal, 2017. 
Berdasarkan Gambar 1 dapat diketahui bahwa jumlah penduduk di Kecamatan Pangkah berjumlah 101.164 jiwa, yang terdiri dari laki-laki dan perempuan dengan jumlah hampir sama, hanya terpaut $0,14 \%$ atau selisih 140 jiwa. Berdasarkan Tabel 1 dapat diketahui bahwa jumlah penduduk di Kecamatan Pangkah menurut umur paling banyak diantara umur 15-64 tahun sebesar 67.336 jiwa atau 66,63\%, dimana pada umur tersebut termasuk dalam usia produktif, sedangkan jumlah penduduk yang paling sedikit di umur 65 tahun keatas sebesar 5.859 jiwa atau $5,80 \%$ dan masuk dalam usia non produktif.

Tabel 2. Jumlah Penduduk menurut Pendidikan di Kecamatan Pangkah Kabupaten Tegal

\begin{tabular}{lrr}
\hline Tingkat Pendidikan & Jiwa & Persentase (\%) \\
\hline SD & 11.030 & 61,27 \\
SMP & 4.342 & 24,12 \\
SMA & 2.631 & 14,61 \\
\hline
\end{tabular}

Sumber : BPS Kabupaten Tegal, 2017.

Berdasarkan Tabel 2 dapat diketahui bahwa pendidikan paling banyak yaitu SD sebesar 11.030 jiwa atau $61,27 \%$. Hal tersebut menunjukan bahwa pendidikan di Kecamatan Pangkah masih didominasi dengan lulusan SD, artinya tingkat pendidikan di Kecamatan Pangkah masih rendah mengingat pemerintah masih mewajibkan untuk sekolah 12 tahun atau setara dengan SMA. Kondisi ini diperlukan adanya perhatian khusus untuk meningkatkan minat masyarakat dalam melanjutkan pendidikannya.

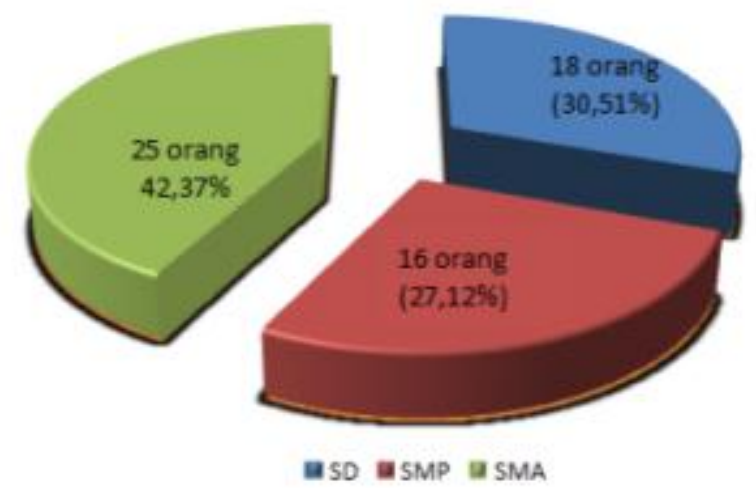

Gambar 2 Pendidikan Responden

Berdasarkan Gambar 2 dapat diketahui bahwa tingkat pendidikan petani responden dominan SMA sebanyak 25 orang atau 42,37\%. Tingkat pendidikan petani sangat berpengaruh terhadap penyerapan teknologi yang dapat meningkatkan kemampuan dan prokdutivitas serta kemahiran seseorang dalam usahataninya. Hal tersebut sesuai dengan pendapat Soekartawi (2003) bahwa 
banyak atau lamanya sekolah pendidikan yang diterima seseorang akan berpengaruh terhadap kecakapannya dalam pekerjaan tertentu.

\section{Umur Responden}

Tabel 3. Identitas Responden Berdasarkan Kelompok Umur

\begin{tabular}{lrr}
\hline Umur (Tahun) & Jumlah (Orang) & Persentase (\%) \\
\hline $39-51$ & 15 & 25,42 \\
$52-64$ & 28 & 47,46 \\
$65-77$ & 16 & 27,12 \\
\hline Jumlah & $\mathbf{5 9}$ & $\mathbf{1 0 0 , 0 0}$ \\
\hline
\end{tabular}

Sumber : Analisis Data Primer, 2018.

Keberhasilan seorang petani dalam mengelola usahataninya sangat dipengaruhi oleh umur atau usia. Umur dapat berpengaruh terhadap kemampuan dan semangat kerja petani dalam mengolah kesehatannya. Petani yang berusia produktif memiliki sifat ketahanan fisik yang lebih besar dibandingkan dengan petani yang berusia non produktif. Berdasarkan Tabel 3 menunjukkan bahwa petani yang memiliki usia non produktif berada pada tingkatan umur 65-77 tahun dengan jumlah petani yaitu 16 orang atau $27,12 \%$. Sementara umur petani produktif antara umur 39-51 dan 52-64 tahun dengan jumlah 43 orang.

\section{Luas Lahan}

Tabel 4. Rata-Rata Luas Lahan Petani Tebu di Kecamatan Pangkah Kabupaten Tegal.

\begin{tabular}{lrr}
\hline Luas Lahan (Ha) & Jumlah (Orang) & Persentase (\%) \\
\hline $1,1-1,5$ & 27 & 45,76 \\
$1,6-2$ & 13 & 22,03 \\
$2,1-2,5$ & 7 & 11,86 \\
$2,6-3$ & 9 & 15,25 \\
$3,1-3,5$ & 3 & 5,08 \\
\hline Jumlah & $\mathbf{5 9}$ & $\mathbf{1 0 0 , 0 0}$ \\
\hline
\end{tabular}

Sumber : Analisis Data Primer, 2018.

Berdasarkan Tabel 4 dapat dilihat bahwa luas lahan yang banyak digunakan untuk budidaya tebu yaitu antara $1,1-1,5$ ha sebanyak 27 orang atau $45,76 \%$. Total luas lahan yang menjadi penelitian yaitu 115,94 ha, dengan lahan milik pribadi seluas 50,44 ha dan lahan sewa seluas 65,5 ha dengan rata-rata luas lahan responden yaitu 1,97 ha, artinya bahwa rata-rata luas lahan petani responden tergolong kedalam luas lahan sedang, hal tersebut sesuai pendapat dari Hernanto (1993) yang menyatakan bahwa yang termasuk golongan luas lahan sempit adalah kurang dari 0,5 ha, dan golongan lahan sedang antara 0,5-2,0 ha dan golongan lahan luas lebih dari 2,0 ha. Besar kecilnya luas lahan dapat mempengaruhi produksi dan pendapatan usahatani, hal tersebut sejalan dengan penelitian dari Soulistyo (2015) yang mengatakan bahwa salah satu faktor yang berpengaruh terhadap usahatani tebu adalah luas lahan. 
Tenaga Kerja

Tabel 5. Jumlah Hari Orang Kerja (HOK) Patani Tebu di Kecamatan Pangkah Kabupaten Tegal.

\begin{tabular}{lrr}
\hline $\begin{array}{l}\text { Hari Orang Kerja } \\
\text { (HOK) (Hari) }\end{array}$ & Jumlah (Orang) & Persentase (\%) \\
\hline $33-50$ & 35 & 59,32 \\
$51-68$ & 15 & 25,42 \\
$69-86$ & 7 & 11,86 \\
$87-104$ & 2 & 3,39 \\
\hline Jumlah & $\mathbf{5 9}$ & $\mathbf{1 0 0 , 0 0}$ \\
\hline
\end{tabular}

Sumber : Analisis Data Primer, 2018.

Tenaga kerja merupakan faktor produksi (input) yang penting dalam usahatani. Penggunaan tenaga kerja akan intensif apabila tenaga kerja yang dikeluarkan dapat memberikan manfaat yang optimal dalam proses produksi dan dapat menggarap tanah seluas tanah yang dimiliki. Jasa tenaga kerja yang dipakai dibayar dengan upah. Berdasarkan Tabel 5 diketahui bahwa jumlah HOK paling tinggi yaitu 33 - 50 hari sebanyak 35 orang atau 59,32\%. Tenaga kerja yang digunakan dalam usahatani tebu menggunakan tenaga kerja laki-laki yang dibayar dengan rata-rata biaya $\mathrm{Rp} 71.000$,-/hari, sedangkan tenaga kerja wanita dibayar dengan rata-rata $\mathrm{Rp} 50.000$,-/hari.

Jumlah Produksi

Tabel 6. Jumlah Produksi Gula Petani Yang Membudidayakan Tebu di Kecamatan Pangkah Kabupaten Tegal

\begin{tabular}{lrr}
\hline Produksi Gula (Kg) & Jumlah (Orang) & Persentase (\%) \\
\hline $4.100-8.000$ & 37 & 62,71 \\
$8.100-13.000$ & 14 & 23,73 \\
$13.100-18.000$ & 8 & 13,56 \\
\hline Jumlah & $\mathbf{5 9}$ & $\mathbf{1 0 0 , 0 0}$ \\
\hline
\end{tabular}

Sumber: Analisis Data Primer, 2018.

Berdasarkan Tabel 6 dapat diketahui bahwa jumlah produksi gula petani tebu dominan $4.100-8.000 \mathrm{~kg}$ berjumlah 37 orang atau 62,71\%. Produksi tebu dipengaruhi oleh curah hujan, rendemen. Curah hujan belum optimal sehingga membuat kandungan gula yang ada di tebu menjadi kurang sempurna. Rendemen tebu sangat dipengaruhi oleh varietas tebu, tingkat kemasakan tebu (umur tanaman tebu) dan kualitas bahan baku sejak di kebun sampai dengan digiling (Marjayanti, 2006). Alokasi penggunaan faktor produksi menentukan produksi yang dihasilkan, semakin optimal penggunaannya, maka produksi tebu juga akan meningkat (Febianti, 2014). Sementara untuk jumlah tetes tebu yang diperoleh petani dapat dilihat pada Tabel 7. Berdasarkan Tabel 7 dapat diketahui bahwa jumlah tetes tebu paling tinggi yaitu $2.000-5.000 \mathrm{~kg}$ sebanyak 41 orang atau $69,49 \%$. 
Tabel 7. Jumlah Tetes Tebu Petani Yang Membudidayakan Tebu di Kecamatan Pangkah Kabupaten Tegal

\begin{tabular}{lrr}
\hline Tetes Tebu (Kg) & Jumlah (Orang) & Persentase (\%) \\
\hline $2.100-4.000$ & 41 & 69,49 \\
$4.100-6.000$ & 7 & 11,86 \\
$6.100-8.000$ & 11 & 18,64 \\
\hline Jumlah & $\mathbf{5 9}$ & $\mathbf{1 0 0 , 0 0}$ \\
\hline
\end{tabular}

Sumber: Analisis Data Primer, 2018.

PEMBAHASAN

Analisis yang digunakan untuk mengetahui pembiayaan adalah dengan menggunakan analisis biaya dari penjumlahan biaya tetap dan biaya variabel, yang digunakan bersama-sama dalam proses produksi, analisis penerimaan, dan analisis pendapatan serta analisis regresi linier berganda.

\section{Biaya Tetap}

Biaya Tetap (Zulkifli, 2003) adalah biaya yang jumlahnya sampai tingkat kegiatan tertentu relatif tetap dan tidak terpengaruh oleh perubahan volume kegiatan. Berikut biaya tetap dalam usahatani tebu dapat dilihat pada Tabel 8 .

Tabel 8. Rata-rata Biaya Tetap Usahatani Tebu di Kecamatan Pangkah.

\begin{tabular}{lrr}
\hline Biaya Tetap & Rata-Rata (Rp/Ha) & Persentase (\%) \\
\hline 1. Pajak & 292.216 & 2,84 \\
2. Sewa lahan & 9.981 .525 & 97,16 \\
\hline Total biaya tetap & $\mathbf{1 0 . 2 7 3 . 7 4 1}$ & $\mathbf{1 0 0 , 0 0}$ \\
\hline
\end{tabular}

Sumber: Analisis Data Primer, 2018.

Berdasarkan Tabel 8 dapat diketahui bahwa total biaya tetap yang dikeluarkan petani tebu Rp 10.273.741 per musim panen. Biaya tetap meliputi biaya pajak tanah dan sewa lahan, hal tersebut sesuai dengan pendapat Hernanto (1991), bahwa biaya yang tergolong kedalam biaya tetap meliputi: pajak tanah, sewa lahan, penyusutan alat, bangunan pertanian dan lain sebagainya. Petani tebu di Kecamatan Pangkah dalam usahataninya tidak mempunyai peralatan seperti cangkul, sabit, dan lain-lain, peralatan tersebut sudah dimiliki oleh buruh tani masing-masing, sehingga tidak dihitung kedalam biaya peralatan. Adapun pembayarannya sudah termasuk kedalam upah yang diterima.

\section{Biaya Variabel}

Biaya variabel adalah biaya yang jumlahnya dapat berubah sesuai dengan besar kecilnya jumlah produksi. Berikut rata-rata biaya variabel dalam usahatani tebu di Kecamatan Pangkah dapat dilihat pada Tabel 9. 
Tabel 9. Rata-Rata Biaya Variabel Dalam Usahatani Tebu Kecamatan Pangkah Kabupaten Tegal

\begin{tabular}{crr}
\hline Biaya Variabel & Rata-rata (Rp) & Persentase (\%) \\
\hline Sewa Alat & 844.068 & 1,89 \\
Biaya Herbisida & 54.771 & 0,12 \\
Biaya Tenaga Kerja & 33.039 .253 & 73,95 \\
Biaya Angkut & 6.287 .018 & 14,07 \\
Biaya Pupuk & 4.446 .558 & 9,95 \\
Lain-lain & 8.475 & 0,02 \\
\hline Jumlah & $\mathbf{4 4 . 6 8 0 . 1 4 3}$ & $\mathbf{1 0 0 , 0 0}$ \\
\hline
\end{tabular}

Sumber: Analisis Data Primer, 2018.

Berdasarkan Tabel 9 dapat diketahui bahwa biaya sewa alat merupakan biaya untuk menyewa pompa air kapasitas 5 PK yang penggunaannya diberikan 3 kali selama satu kali musim panen. Herbisida yang digunakan yaitu round up yang fungsinya untuk membasmi gulma golongan rumput-rumputan. Tenaga kerja merupakan tenaga kerja dari luar keluarga yang meliputi tenaga kerja kepras, penyemprotan, penyiraman, pembumbunan, pemupukan, putus akar, dan klentek, serta tebang angkut. Angkut tebu menggunakan sistem Bundle cane dimana, sistem tersebut sepenuhnya dikerjakan oleh tenaga tebang dengan tebu ditebang, dikumpulkan, diikat sekitar $50 \mathrm{~kg}$ dan dimuat kedalam truk yang kemudian membawanya ke pabrik gula. Semua pekerjaan dilakukan secara manual. Pupuk yang digunakan petani tebu di Kecamatan Pangkah berupa pupuk kimia meliputi ZA dan Phonska (6:4). Biaya lain-lain tersebut digunakan untuk nutrisi tebu (nutralindo) agar tonase yang dihasilkan bisa meningkat.

\section{Biaya Total}

Biaya total merupakan biaya dari penjumlahan biaya tetap dan biaya variabel yang digunakan dalam proses produksi. Berikut rata-rata total biaya usahatani tebu di Kecamatan Pangkah dapat dilihat pada Tabel 10. Berdasarkan Tabel 10 diketahui biaya total usahatani tebu adalah Rp 54.953.884 per musim panen dengan rata-rata luas lahan 1,97 ha.

Tabel 10. Rata-Rata Total Biaya Usahatani Tebu di Kecamatan Pangkah Kabupaten Tegal.

\begin{tabular}{lcr}
\hline Biaya Total & Biaya (Rp) & Persentase \% \\
\hline Biaya Tetap & 10.273 .241 & 18,70 \\
Biaya Variabel & 44.680 .143 & 81,30 \\
\hline Jumlah & $\mathbf{5 4 . 9 5 3 . 8 8 4}$ & $\mathbf{1 0 0 , 0 0}$ \\
\hline
\end{tabular}

Sumber : Analisis Data Primer, 2018.

\section{Penerimaaan}

Berdasarkan Tabel 11 menunjukkan bahwa penerimaan usahatani tebu bersumber dari jumlah produksi gula yang dihasilkan dan jumlah tetes tebu dengan total penerimaan usahatani tebu sebesar Rp. 82.979.127 per musim panen. 
Tabel 11. Rata-Rata Total Penerimaan Usahatani Tebu di Kecamatan Pangkah Kabupaten Tegal.

\begin{tabular}{lrrr}
\hline Keterangan & Jumlah & Harga & Total \\
\hline Produksi Gula(Kg) & 8.098 & 9.600 & 77.740 .964 \\
Tetes $(\mathrm{Kg})$ & 4.029 & 1.300 & 5.238 .163 \\
\hline Jumlah & & & $\mathbf{8 2 . 9 7 9 . 1 2 7}$ \\
\hline
\end{tabular}

Sumber : Analisis Data Primer, 2018.

\section{Pendapatan}

Tabel 12. Rata-rata Pendapatan Usahatani Tebu Kecamatan Pangkah Kabupaten Tegal.

\begin{tabular}{lr}
\hline Keterangan & Jumlah \\
\hline Penerimaan (Rp) & 82.979 .127 \\
Biaya Total Produksi (Rp) & 54.953 .884 \\
\hline Pendapatan (Rp) & $\mathbf{2 8 . 0 2 5 . 2 4 3}$ \\
\hline
\end{tabular}

Sumber: Analisis Data Primer, 2018.

Berdasarkan Tabel 12 dapat diketahui bahwa rata-rata jumlah penerimaan usahatani tebu di Kecamatan Pangkah Kabupaten Tegal sebesar Rp.82.979.127 per musim panen dengan jumlah rata-rata biaya total produksi sebesar Rp. 54.953.884 per musim panen, maka dapat di peroleh pendapatan rata-rata usahatani sebesar Rp 28.025.243 per musim panen. Berdasarkan hasil pengujian tersebut menunjukkan bahwa usahatani tebu di Kecamatan Pangkah Kabupaten Tegal memperoleh pendapatan.

\section{Analisis Regresi Linier Berganda}

Tabel 13. Hasil Analisis Regresi Pendapatan Usahatani Tebu di Kecamatan Pangkah Kabupaten Tegal.

\begin{tabular}{cllll}
\hline No. & Variabel & Koefisien Regresi & T-hitung & Sig \\
\hline 1. & Konstanta & 19433344,85 & 2,723 & 0,009 \\
2. & Pendidikan & 614617,529 & 2,080 & $0,042^{*}$ \\
3. & Umur & $-298176,548$ & $-3,502$ & $0,001^{* *}$ \\
4. & Luas Lahan & $-561,830$ & $-2,066$ & $0,044 *$ \\
5. & Tenaga Kerja & $-288948,347$ & $-3,568$ & $0,001^{* *}$ \\
6. & Produksi & 5715113,062 & 9,201 & $0,000^{* *}$ \\
7. & Koefisien Determinasi $\left(\mathrm{R}^{2}\right)$ & 0,848 & & \\
8. & R Square & 0,861 & \\
9. & F hitung & & \\
10. & F tabel 1\% & 65,561 & \\
11. & T tabel 1 \% & 3,38 & \\
12. & T tabel 5\% & & \\
13. & Durbin Watson & 2,39879 & \\
**Signifikan pada tingkat kepercayaan $99 \%(\mathrm{p}=0,01)$ & & \\
* Signifikan pada tingkat kepercayaan $95 \%(\mathrm{p}=0,05)$ & &
\end{tabular}


Berdasarkan hasil analisis regresi linear berganda pada Tabel 13 menunjukkan bahwa persamaan regresi yang terbentuk adalah sebagai berikut:

$$
\begin{aligned}
Y= & 19433344,85+614617,529 X_{1}-298176,548 X_{2}-561,830 X_{3}+5715113,062 \\
& X_{4}-288948,347 X_{5}+e
\end{aligned}
$$

Keterangan :

$\mathrm{Y}=$ Pendapatan usahatani tebu $(\mathrm{Rp})$

$\mathrm{X}_{1}=$ Pendidikan (Tahun)

$\mathrm{X}_{2}=$ Umur (Tahun)

$\mathrm{X}_{3}=$ Luas lahan $(\mathrm{Ha})$

$\mathrm{X}_{4}=$ Tenaga kerja (Hok)

$\mathrm{X}_{5}=$ Jumlah produksi $(\mathrm{Kg})$

\section{UJI ASUMSI KLASIK}

Dalam penelitian ini digunakan uji normalitas, uji multikolinearitas, uji autokorelasi dan uji heteroskedastisitas yang telah diuji menggunakan SPSS 21.0 dan dinyatakan terbebas dari keempat uji tersebut.

\section{UJI STATISTIK}

\section{Uji Koefisien Determinan $\left(\mathbf{R}^{2}\right)$}

Besar koefisien determinan atau nilai $\mathrm{R}^{2}$ sebesar 0,848 menunjukkan bahwa semua variabel independen (pendidikan, umur, luas lahan, tenaga kerja, jumlah produksi) dapat menjelaskan variabel dependent (pendapatan) sebesar $84,8 \%$, sedangkan sisanya $15,2 \%$ di jelaskan variabel lain.

\section{Uji F}

Berdasarkan hasil analisa pada Tabel 13 diperoleh nilai $\mathrm{F}$ hitung 65,561 lebih besar dibanding dengan nilai $\mathrm{F}_{\text {tabel }}$ sebesar 3,38 atau dapat dilihat pada nilai probabilitas signifikan sebesar 0,000 lebih kecil dari 0,01 artinya sangat signifikan. Hal ini berarti bahwa pendapatan usahatani tebu secara bersama-sama mampu dijelaskan oleh variabel pendidikan, umur, luas lahan, tenaga kerja, jumlah produksi.

\section{Uji t}

Hasil output SPSS faktor-faktor yang mempengaruhi pendapatan usahatani tebu di Kecamatan Pangkah Kabupaten Tegal dengan menggunakan uji t adalah pendidikan, umur, luas lahan, tenaga kerja, jumlah produksi. Hal tersebut dilihat dari nilai signifikan $<0,05$. Secara individu variabel-variabel tersebut berpengaruh pada pendapatan usahatani tebu.

Pendidikan diperoleh $\mathrm{t}_{\text {hitung }} 2,080>\mathrm{t}$ tabel 2,005 dengan nilai signifikan 0,042. Signifikan kurang dari 0,05 maka nilai thitung sebesar 2,080 signifikan pada taraf a $=5 \%$. Faktor pendidikan berpengaruh nyata terhadap pendapatan usahatani tebu dengan koefisien regresi sebesar 614.617,529 berarti semakin tinggi tingkat pendidikan petani, maka ada kecenderungan pendapatan usahatani akan meningkat sebesar $614.617,529,-$. Hal tersebut sejalan dengan penelitian dari Saleh (2012) yang menjelaskan bahwa pendidikan berhubungan positif dan signifikan terhadap pendapatan usahatani tebu di Desa Gunung Anyar Kecamatan 
Tapen Kabupaten Bondowoso. Tingkat pendidikan responden paling banyak adalah SMA. Tingkat pendidikan akan berpengaruh pada penerapan inovasi baru, sikap mental dan perilaku tenaga kerja dalam usahatani. Tingkat pendidikan yang lebih tinggi akan lebih mudah dalam penerapan inovasinya. Pendidikan petani tidak hanya berorientasi terhadap peningkatan produksinya tetapi juga mengenai kehidupan sosial masyarakat tani (Soeharjo dan Patong, 1999).

Umur diperoleh $\mathrm{t}_{\text {hitung }}-3,502>\mathrm{t}_{\text {tabel }} 2,398$ dengan nilai signifikan 0,001 . Signifikan kurang dari 0,01 maka nilai thitung sebesar -3,502 signifikan pada taraf $a=1 \%$. Faktor Umur berpengaruh sangat nyata terhadap pendapatan usahatani tebu dengan koefisien regresi sebesar -298.176,548 yang berarti jika penambahan satu macam input sedangkan yang lain tetap, maka tambahan output yang dihasilkan dari penambahan input tersebut mula-mula naik tetapi selanjutnya menurun sebesar -298.176,548. Hal tersebut terjadi karena semakin bertambah tua umur petani tebu akan mempengaruhi intensitas waktu saat di lahan serta terbatasnya tenaga yang dikeluarkan untuk usahataninya. Hal tersebut sesuai dengan pendapat Hasyim (2006) bahwa umur petani merupakan salah satu faktor yang berhubungan dengan kemampuan kerja petani dalam melaksanakan kegiatan usahataninya.

Luas lahan diperoleh $\mathrm{t}_{\text {hitung }}-2,066>\mathrm{t}$ tabel 2,005 dengan nilai signifikan

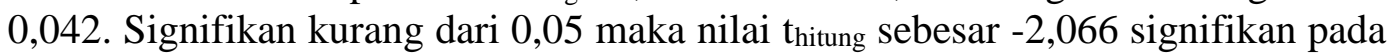
taraf $a=5 \%$. Faktor luas lahan berpengaruh nyata terhadap pendapatan usahatani tebu dengan koefisien regresi sebesar $-561,830$ yang berarti jika penambahan satu macam input sedangkan yang lain tetap, maka tambahan output yang dihasilkan dari penambahan input tersebut mula-mula naik tetapi selanjutnya menurun sebesar -561,830. Hal tersebut terjadi karena semakin bertambahnya lahan menjadikan biaya sewa lahan petani tebu menjadi meningkat, mengingat lahan tebu milik petani merupakan lahan sewa dengan luas 65,05 ha. Luas lahan yang besar belum tentu mendapatkan hasil yang maksimal (Yanutya, 2013). Luas tanah garapan akan mempengaruhi skala usaha yang pada akhirnya akan mempengaruhi efisien atau tidaknya lahan tersebut (Kustini, 1985).

Tenaga kerja diperoleh $t_{\text {hitung }}-3,568>t_{\text {tabel }}$ 2,398 dengan nilai signifikan 0,001. Signifikan kurang dari 0,01 maka nilai thitung sebesar $-3,568$ signifikan pada taraf $a=1 \%$. Faktor tenaga kerja berpengaruh sangat nyata terhadap pendapatan usahatani tebu dengan koefisien regresi sebesar -288.948,347 yang berarti jika penambahan satu macam input sedangkan yang lain tetap, maka tambahan output yang dihasilkan dari penambahan input tersebut mula-mula naik tetapi selanjutnya menurun sebesar $-288.948,347$. Hal tersebut terjadi karena berkurangnya tenaga ahli tebang dan minimnya kaderisasi menjadikan biaya tebang tebu kian mahal, terlebih dengan adanya tambahan yang seringkali diminta oleh tenaga tebang, dalam bahasa Tegal disebut "prelek" dan "setut". Hal tersebut sesuai dengan Soekartawi (2002) bahwa semakin tinggi upah tenaga kerja maka akan menurunkan pendapatan uasahatani.

Jumlah produksi diperoleh $t_{\text {hitung }} 9,201>\mathrm{t}_{\text {tabel }}$ 2,398 dengan nilai signifikan 0,000. Signifikan kurang dari 0,01 maka nilai thitung sebesar 9,201 signifikan pada taraf $\mathrm{a}=1 \%$. Faktor produksi berpengaruh sangat nyata terhadap pendapatan usahatani tebu dengan koefisien regresi sebesar 5.715.113,062 berarti semakin 
tinggi tingkat pendidikan petani, maka ada kecenderungan pendapatan usahatani akan meningkat sebesar 5.715.113,062. Produksi tebu dipengaruhi oleh curah hujan, rendemen. Curah hujan belum optimal sehingga membuat kandungan gula yang ada di tebu menjadi kurang sempurna, untuk pembentukan gula dibutuhkan kondisi lingkungan yang kering. Sementara rendemen berdampak pada jumlah kristal yang terkandung dalam gula. rendemen merupakan kandungan gula yang ada di tebu. Rendemen tebu sangat dipengaruhi oleh varietas tebu, tingkat kemasakan tebu (Umur tanaman tebu) dan kualitas bahan baku sejak di kebun sampai dengan digiling (Marjayanti, 2006). Sementara itu, umur tebu yang tepat untuk ditebang ditentukan oleh jadwal tanam dan tebang tebu akan meningkatkan produktivitas tebu di tingkat petani (Susila dan Hutagaol, 2005). Selain itu lamanya giling berpengaruh nyata terhadap produksi gula (Wahyuni, 2007).

\section{KESIMPULAN DAN SARAN \\ Kesimpulan}

Berdasarkan hasil penelitian "Faktor-Faktor Yang Mempengaruhi Pendapatan Usahatani Tebu di Kecamatan Pangkah Kabupaten Tegal" dapat disimpulkan bahwa:

1. Rata-rata biaya total produksi usahatani tebu sebesar $\mathrm{Rp} 54.953 .884$ per musim panen, dengan rata-rata penerimaan usahatani tebu dalam satu kali panen $\mathrm{Rp}$ 82.979.127. Selisih rata-rata penerimaan dan rata-rata biaya total produksi diperoleh pendapatan usahatani tebu dengan rata-rata pendapatan sebesar Rp 28.025.243 per musim panen dengan rata-rata luas lahan 1,97 ha.

2. Faktor-faktor yang mempengaruhi pendapatan usahatani tebu di Kecamatan Pangkah Kabupaten Tegal meliputi pendidikan, umur, luas lahan, tenaga kerja, dan jumlah produksi, selain itu, nilai koefisien determinan atau nilai $\mathrm{R}^{2}$ sebesar 0,848 menunjukkan bahwa variasi fakktor pendapatan usahatani tebu dapat dijelaskan oleh semua variabel bebas sebesar 84,8\%, sedangkan sisanya $15,2 \%$ di jelaskan variabel lain yang tidak dimasukkan kedalam model. Faktor yang berpengaruh nyata berdasarkan uji t adalah pendidikan dan luas lahan, sedangkan yang berpengaruh sangat nyata adalah umur, tenaga kerja, dan jumlah produksi.

\section{Saran}

1. Kegiatan penyuluhan dan pendampingan terhadap petani sebaiknya dilaksanakan secara efektif aktif dan berkelanjutan agar informasi penggunaan faktor-faktor produksi usahatani tebu yang dapat meningkatkan produksi dapat di aplikasikan sehingga petani dalam mengusahakan tebunya sesuai dengan Standar Operasional Prosedur (SOP) dan mendapatkan hasil yang maksimal dari usahatani tersebut.

2. Perlu adanya manajemen tebang angkut secara mandiri untuk menekan pengeluaran biaya tebang tebu.

3. Perlu adanya peraturan pemerintah yang mengatur tentang kebijakan harga gula. 


\section{DAFTAR PUSTAKA}

Febianti, D, I. 2014. Efisiensi Usaha Tani Tebu di Kabupaten Purworejo. Jurnal Agro Ekonomi Vol. 26 Nomor 21. Yogyakarta: UGM

Hasyim, H. 2006. Analisis Faktor Hubungan Sosial Ekonomi Petani Terhadap Program Penyuluhan Pertanian. Penelitian LP Universitas Sumatra Utara. Medan.

Hernanto, F. 1991. Ilmu Usahatani. Jakarta: Penebar Swadaya.

Hernanto, F. 1993. Ilmu Usahatani. Jakarta: Penebar Swadaya.

BPS, 2017. Kecamatan Pangkah Dalam Angka Tahun 2017. BPS Kabupaten Tegal: Author.

Kustini. 1985. Pengantar Ilmu Manajemen. Jakarta: PT. Pronhalindo.

Marjayanti, S. 2006. Analisis Kemasakan Untuk Menentukan saat Tebang Optimal. Pasuruan: P3GI

Prabowo, Rossi (2010). "Kebijakan Pemerintah Dalam Mewujudkan Ketahanan Pangan Di Indonesia" Jurnal Mediagro Vol 6. No.2 2010. Hal 62-73

Royyani, M.F., Lestari. 2009. Peran Indonesia dalam Penciptaan Peradaban Dunia: Perspektif Botani. Subang: Puslit biologi LIPI.

Saleh, Mohammad. 2012. Faktor Yang Mempengaruhi Pendapatan Kelompok Petani Tebu di Desa Gunung Anyar Kecamatan Tapen Kabupaten Bondowoso. Jurnal ISEI Jember Vol. 2 Nomor 1. Jember: Universitas Jember.

Soeharjo, Patong, D. 1999. Sendi- Sendi Proyek Ilmu Usahatani. Departemen Ilmu-Ilmu Sosial. Institute Pertanian Bogor.

Soekartawi. 2002. Analisis Usahatani. Jakarta: UI-PRESS.

Soekartawi.2003. Teori Ekonomi Produksi Dengan Pokok Bahasan Analisis Fungsi Cobb-Douglas, cetakan ke 3. Jakarta: Rajawali Press.

Soetrisno, L. 2002. Paradigma Baru Pembangunan Pertanian Sebuah Tinjauan Sosiologis. Yogyakarta: Kanisius.

Soulistyo, A, T. 2015. Faktor-Faktor Yang Mempengaruhi Pendapatan Usaha Tani Tebu Anggota KUD Bulusae Kabupaten Lumajang. Skripsi. UGM 
Susila WR, Hutagaol MP. 2005. Model Keterpaduan Jadual Tanam Dan Tebang Tebu: Pendekatan Kompromi. Jurnal Manajemen Dan Agribisnis 2(2):129-144. Bogor: Institut Pertanian Bogor.

Wahyuni, I,T. 2007. Analisis Efisiensi Produksi gula di PG Madukismo Yogyakarta. Skripsi. Bogor: Departemen Agribisnis. Fakultas Manajemen dan Ekonomi. Institut Pertanian Bogor.

Yanutya, P.A.T. 2013. Analisis Pendapatan Petani Tebu di Kecamatan Jepon Kabupaten Blora. Jurnal Ekonomi Pembangunan EDAJ 2 (4). Semarang: Universitas Negeri Semarang.

Zulkifli, A. 2003. Manajemen Sistem Informasi. Jakarta: PT. Gramedia Pustaka Utama 